NASA/TM-2008-215303

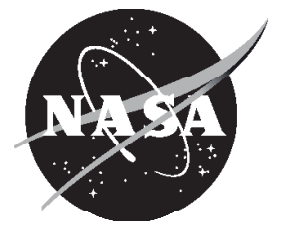

\title{
A Modular Aero-Propulsion System Simulation of a Large Commercial Aircraft Engine
}

Jonathan A. DeCastro

Impact Technologies, LLC, Rochester, New York

Jonathan S. Litt

Glenn Research Center, Cleveland, Ohio

Dean K. Frederick

Saratoga Control Systems, Inc., Saratoga Springs, New York 


\section{NASA STI Program . . . in Profile}

Since its founding, NASA has been dedicated to the advancement of aeronautics and space science. The NASA Scientific and Technical Information (STI) program plays a key part in helping NASA maintain this important role.

The NASA STI Program operates under the auspices of the Agency Chief Information Officer. It collects, organizes, provides for archiving, and disseminates NASA's STI. The NASA STI program provides access to the NASA Aeronautics and Space Database and its public interface, the NASA Technical Reports Server, thus providing one of the largest collections of aeronautical and space science STI in the world. Results are published in both non-NASA channels and by NASA in the NASA STI Report Series, which includes the following report types:

- TECHNICAL PUBLICATION. Reports of completed research or a major significant phase of research that present the results of NASA programs and include extensive data or theoretical analysis. Includes compilations of significant scientific and technical data and information deemed to be of continuing reference value. NASA counterpart of peer-reviewed formal professional papers but has less stringent limitations on manuscript length and extent of graphic presentations.

- TECHNICAL MEMORANDUM. Scientific and technical findings that are preliminary or of specialized interest, e.g., quick release reports, working papers, and bibliographies that contain minimal annotation. Does not contain extensive analysis.

- CONTRACTOR REPORT. Scientific and technical findings by NASA-sponsored contractors and grantees.

- CONFERENCE PUBLICATION. Collected papers from scientific and technical conferences, symposia, seminars, or other meetings sponsored or cosponsored by NASA.

- SPECIAL PUBLICATION. Scientific, technical, or historical information from NASA programs, projects, and missions, often concerned with subjects having substantial public interest.

- TECHNICAL TRANSLATION. Englishlanguage translations of foreign scientific and technical material pertinent to NASA's mission.

Specialized services also include creating custom thesauri, building customized databases, organizing and publishing research results.

For more information about the NASA STI program, see the following:

- Access the NASA STI program home page at http://www.sti.nasa.gov

- E-mail your question via the Internet to help@ sti.nasa.gov

- Fax your question to the NASA STI Help Desk at 301-621-0134

- Telephone the NASA STI Help Desk at 301-621-0390

- Write to: NASA Center for AeroSpace Information (CASI) 7115 Standard Drive Hanover, MD 21076-1320 
NASA/TM-2008-215303

AIAA-2008-4579

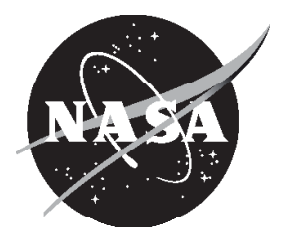

\section{A Modular Aero-Propulsion System Simulation of a Large Commercial Aircraft Engine}

Jonathan A. DeCastro

Impact Technologies, LLC, Rochester, New York

Jonathan S. Litt

Glenn Research Center, Cleveland, Ohio

Dean K. Frederick

Saratoga Control Systems, Inc., Saratoga Springs, New York

Prepared for the

44th Joint Propulsion Conference and Exhibit

cosponsored by AIAA, ASME, SAE, and ASEE

Hartford, Connecticut, July 21-23, 2008

National Aeronautics and

Space Administration

Glenn Research Center

Cleveland, Ohio 44135 


\section{Acknowledgments}

The authors wish to acknowledge Don Simon of NASA Glenn Research Center for his contributions in the development of the steady state solver, Shreeder Adibhatla of General Electric Aircraft Engines for many informative discussions on engine control, N\&R Engineering, Inc., for facilitating the controller development, Sanjay Garg of NASA Glenn for his vision and support in the creation of C-MAPSS, and the NASA Aviation Safety Program

Integrated Resilient Aircraft Control Project for funding this work.

Trade names and trademarks are used in this report for identification only. Their usage does not constitute an official endorsement, either expressed or implied, by the National Aeronautics and Space Administration.

Level of Review: This material has been technically reviewed by technical management.

Available from

NASA Center for Aerospace Information 7115 Standard Drive

Hanover, MD 21076-1320
National Technical Information Service 5285 Port Royal Road Springfield, VA 22161

Available electronically at http://gltrs.grc.nasa.gov 


\title{
A Modular Aero-Propulsion System Simulation of a Large Commercial Aircraft Engine
}

\author{
Jonathan A. DeCastro \\ Impact Technologies, LLC \\ Rochester, New York 14623 \\ Jonathan S. Litt \\ National Aeronautics and Space Administration \\ Glenn Research Center \\ Cleveland, Ohio 44135 \\ Dean K. Frederick \\ Saratoga Control Systems, Inc. \\ Saratoga Springs, New York 12866
}

\begin{abstract}
A simulation of a commercial engine has been developed in a graphical environment to meet the increasing need across the controls and health management community for a common research and development platform. This paper describes the Commercial Modular Aero Propulsion System Simulation (C-MAPSS), which is representative of a 90,000-lb thrust class two spool, high bypass ratio commercial turbofan engine. A control law resembling the state-of-the-art on board modern aircraft engines is included, consisting of a fan-speed control loop supplemented by relevant engine limit protection regulator loops. The objective of this paper is to provide a top-down overview of the complete engine simulation package.
\end{abstract}

\section{Nomenclature}

$\begin{array}{ll}e & \text { solver error } \\ \text { HPC } & \text { high pressure compressor } \\ \text { HPT } & \text { high pressure turbine } \\ J & \text { solver Jacobian } \\ \text { LPC } & \text { low pressure compressor } \\ \text { LPT } & \text { low pressure turbine } \\ \text { MM } & \text { model matching control design scheme } \\ M N & \text { Mach number } \\ N_{1} & \text { fan speed } \\ N_{1}^{R} & \text { corrected fan speed } \\ N_{2} & \text { core speed } \\ N_{2}^{R} & \text { corrected core speed } \\ P_{i} & \text { pressure at station } i \\ P R & \text { pressure ratio } \\ S M & \text { stall margin } \\ T_{i} & \text { temperature at station } i \\ \text { TRA } & \text { throttle resolver angle }\end{array}$




$\begin{array}{ll}\text { VBV } & \text { variable bleed valve } \\ \text { VSV } & \text { variable stator vane } \\ W f & \text { fuel flow } \\ W_{i} & \text { flow at station } i \\ x & \text { solver state } \\ \varphi_{i} & \text { corrected mass flow rate at station } i \\ \eta & \text { adiabatic efficiency }\end{array}$

\section{Introduction}

There is great interest in the development of advanced control and health management algorithms for aircraft turbofan engines. However, a practical yet realistic non-proprietary simulation of a commercial turbofan engine did not previously exist on which to develop these algorithms. This has been a barrier to progress, especially in regard to collaboration between NASA researchers and their counterparts in academia and industry who must develop their new technologies in a realistic test-bed. Previously, a NASA-developed generic military turbofan engine simulation, the Modular Aero-Propulsion System Simulation (MAPSS), had been released for public use as a means to rapidly implement and test control algorithms on a validated engine model (ref. 1). Since then, other industrial and military gas turbine models tailored for controls and diagnostics research have been described in some recent papers as platforms in support of various programs (refs. 2 to 5). However, most of these are not available to the general public. Because many problems of interest are directly applicable to the commercial platform, there remains a strong need for a common non-proprietary commercial engine simulation from those in the community. Indeed, the differences between the commercial and military platforms are significant. Aside from the obvious differences in thermodynamic operation, the actuators, sensors, time constants, controller, and solution method are categorically dissimilar.

The Commercial Modular Aero-Propulsion System Simulation (C-MAPSS) has been developed in the Matlab/Simulink (The Mathworks, Inc.) environment as a multifunctional simulation of a large commercial turbofan engine with a realistic engine control system. The engine represents a modern dualspool, high-bypass ratio turbofan engine of the type on which many controls and diagnostics/health management studies have concentrated in recent years. The key function of C-MAPSS is to provide the user with a graphical turbofan engine simulation environment in which advanced algorithms can be implemented and tested. The software provides the user easy access to health, control, and engine parameters through a graphical user interface (GUI). A controller that is representative of the control logic within a Full Authority Digital Engine Controller (FADEC) on board current commercial engines is also part of the package.

The C-MAPSS paradigm provides functionality for the following: engine initialization at arbitrary (valid) flight conditions in the flight envelope, generation of linear point models at operating conditions for system analysis and design, design of linear point compensators, and rapid generation of closed-loop simulations and visualization of the results. All of these capabilities have been automated for the end user through use of the Matlab GUI environment. The usually tedious task of constructing a gain-scheduled controller, for example, may be greatly facilitated by the GUI's built-in capabilities. To be specific, the design of a point controller, as an elemental part of the gain-scheduled controller, is consolidated into a point-and-click operation that leverages the data capture/retrieval capabilities of Matlab. The basic features are supplemented with capabilities to simulate effects such as engine deterioration or faults by adjustment of the health parameter modifiers, as is common practice.

Each of the basic engine components has been coded as a Simulink s-function script (a computer program, interpreted or compiled, written in one of several standard programming languages within a Simulink block), which brings several advantages including execution speed and line-by-line validation/modification. Owing to the Matlab/Simulink environment in which it was developed, the model is capable of being eventually deployed (all or in part) as compiled code for hardware-in-the-loop 
applications such as flight simulators and other real-time validation studies. This would require further development, and is not within the scope of this paper.

It should be noted that C-MAPSS has been made available as an initial release (version 1.0) through the NASA Glenn Software Repository website (http://technology.grc.nasa.gov/software/) and has been reported in reference 6 . A more recent version that has been developed (to be designated version 2.0 in a possible future release) is the focus of this paper. The second version differs from the first release in a number of areas. First, several new model features have been added. These include actuator and sensor dynamics, variable geometry effects, Reynolds' number effects (in the high pressure compressor), and representation of the combustion transport delay. Changes have been made to the gain-scheduled controller structure and implementation of the limit logic. Several improvements have been made to the GUI to offer the user greater flexibility in performing the built-in functions in a more streamlined manner.

The following sections outline the basic engine model from a top-down perspective. Section II presents important details of the C-MAPSS engine and provides some scope of the modeling techniques used for this engine system. Implementation details of the aero-thermodynamic model, the solution method, and the control logic are described in Section III. A simple flight scenario example, highlighting aspects of the simulation's functionality as a controls and diagnostics development and prototyping tool, is presented in Section IV. Section V summarizes the C-MAPSS program.

\section{Overview of the C-MAPSS Engine Platform}

The C-MAPSS engine represents a conceptual 90,000-lb thrust class turbofan engine with highbypass ratio and a two-spool configuration. Figure 1 shows the various components of the engine. The five rotating components consist of the fan, low pressure compressor (LPC), and low pressure turbine (LPT) on the fan shaft, and the high pressure compressor (HPC) and high pressure turbine (HPT) on the core shaft. The station designations are shown along the bottom of the figure. To give some perspective for size, the engine has been designed to operate with a bypass ratio (BPR) of 8.4, an overall pressure ratio (OPR) of 36, and has a fan diameter of approximately $100 \mathrm{in}$. The design speeds for the fan and core shafts are 2450 and $9300 \mathrm{rpm}$, respectively. The control inputs to this engine are fuel flow $(\mathrm{Wf})$, variable stator vane (VSV) angle, and variable bleed valve (VBV) position. Two spool rotation and six gas path sensors are considered as inputs to the control logic: $N_{1}, N_{2}, P_{20}, T_{20}, T_{24}, P_{S_{30}}, T_{48}$, and $P_{50}$. This is representative of the sensors, in terms of type and quantity, used in most commercial turbofan engines.

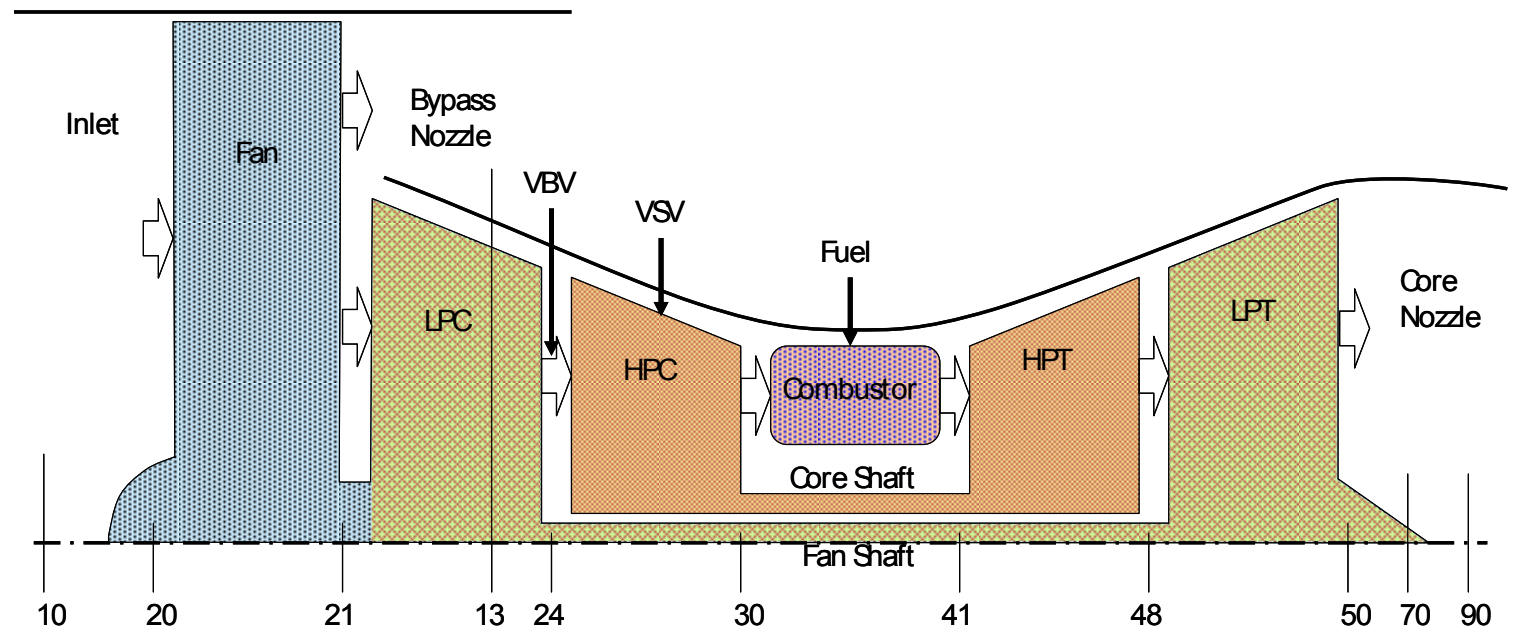

Figure 1.-Diagram of the C-MAPSS engine components and station designations. 
The component maps and other parametric data have been generated at NASA using a variety of high-fidelity sources. The map data are loaded at startup from Matlab script files, which are then read as global variables at the component s-function level. As such, the simulation is easy to adapt with different cycle deck data representative of different turbofan engines. The model has been constructed to ensure steady-state validity over altitudes ranging from sea level to 40,000 ft, Mach numbers (MN) between zero and 0.85 , and sea-level temperatures between -60 and $103^{\circ} \mathrm{F}$. Details of the implementation are discussed in the remainder of the paper.

\section{Description of the Engine Model and Control System}

This section is devoted to providing the reader with an understanding of the formulation and construction of the aero-thermodynamic model and control system. In addition to providing an overview of the modeling method, this section details the conventions used for modeling physical features such as stall margin, health parameters and component maps. Detailed accounts of the thermodynamic models for gas turbines can be found elsewhere in the literature (refs.7 to 10).

\section{A. Aero-Thermodynamic Model}

In order to capture the essential thermodynamic effects of the five rotating components, each has been represented by maps relating pressure ratio, corrected flow rate, and adiabatic efficiency, which are indexed by corrected shaft speed. The procedure and conventions for correcting gas path flow rates $W$ and spool speeds are well known and well documented (see ref. 11). The corrected mass flow rates are designated by " $\varphi$ " and the corrected versions of the two spool speeds are designated " $N_{1}^{R}$ " and " $N_{2}^{R}$."

The model operates with thermodynamic parameters that vary with temperature and gas composition. When computing these parameters, it is assumed that the combustion is complete with no unburned combustion products. The polytropic coefficient, for example, is calculated based on the gas temperature and fuel-to-air ratio (FAR). The universal gas constant is computed based only upon the fuel-to-air ratio.

\section{Atmospheric Mode}

In order to represent altitude-adjusted air properties, the C-MAPSS package includes an atmospheric model consisting of an altitude-adjusted free-stream temperature. For researchers intending to integrate CMAPSS with an airframe model, the atmospheric model can be replaced with the aircraft atmospheric model to maintain consistency.

\section{Inlet}

The simple model of the inlet consists of a total pressure and temperature computation that is corrected to account for ram pressure recovery. Since C-MAPSS only operates in the subsonic regime, ram recovery typically stays above 99.5 percent.

\section{Fan and Compressors}

In the fan and compressors, the torque supplied by the shaft is used to compress the flow. The fan, low pressure compressor (LPC) and high pressure compressor (HPC) are each represented by a performance map that is described by three quantities: pressure ratio $(P R), \varphi$, and adiabatic efficiency $(\eta)$. These maps are indexed by shaft speed and $R$-line. The independent variable $R$-line is used instead of $P R$ simply because compressor maps take on a profile such that a given $P R$ may correspond to more than one corrected flow value at a constant corrected speed. An $R$-line value of 1.0 corresponds to the stall line and an $R$-line of 2.0 corresponds to the intersection with the design point. Inter-stage bleeds representing air extracted for customer service, preferential cooling, and overboard bleed have been included as fractional

flow debits on the core stream. These have been assumed to be localized at the compressor exit ( $9^{\text {th }}$ stage), which is a reasonable approximation to make even though the actual bleeds may occur, in some cases, 
several stages upstream. Table 1 shows the design-point characteristics of the fan and compressors, which gives the generalist an idea of the size of each component, and may be used as a basis for scaling the entire map to assume the form of a different engine cycle.

TABLE 1.-FAN/COMPRESSOR/TURBINE

DESIGN POINT CHARACTERISTICS

\begin{tabular}{|l|l|l|}
\hline Component & Parameter & Value \\
\hline & $N_{1}$ & $2654 \mathrm{rpm}$ \\
& $R_{\text {-line }}$ Fan & 2.0 \\
& $P R_{\text {Fan }}$ & 1.784 \\
& $\eta_{\text {Fan }}$ & 0.8969 \\
& $\varphi_{\text {Fan }}$ & $3655.5 \mathrm{lbm} / \mathrm{s}$ \\
\hline & $N_{1}$ & $2654 \mathrm{rpm}$ \\
Low Pressure & $R$-line & 2.0 \\
Compressor & $P R_{\mathrm{LPC}}$ & 1.1035 \\
& $\eta_{\mathrm{LPC}}$ & 0.9148 \\
& $\varphi_{\mathrm{LPC}}$ & $289.57 \mathrm{lbm} / \mathrm{s}$ \\
\hline & $N_{2}$ & $9210 \mathrm{rpm}$ \\
High Pressure & $R$-line & 2.0 \\
Compressor & $P R_{\mathrm{HPC}}$ & 21.817 \\
& $\eta_{\mathrm{HPC}}$ & 0.8615 \\
& $\varphi_{\mathrm{HPC}}$ & $209.47 \mathrm{lbm} / \mathrm{s}$ \\
\hline \multirow{3}{*}{ High Pressure } & $N_{2}$ & $9119 \mathrm{rpm}$ \\
Turbine & $P R_{\mathrm{HPT}}$ & 4.239 \\
& $\eta_{\mathrm{HPT}}$ & 0.9202 \\
& $\varphi_{\mathrm{HPT}}$ & $17.59 \mathrm{lbm} / \mathrm{s}$ \\
\hline \multirow{3}{*}{ Low Pressure } & $N_{1}$ & $2394 \mathrm{rpm}$ \\
Turbine & $P R_{\mathrm{LPT}}$ & 5.858 \\
& $\eta_{\mathrm{LPT}}$ & 0.930 \\
& $\varphi_{\mathrm{LPT}}$ & $94.64 \mathrm{lbm} / \mathrm{s}$ \\
\hline
\end{tabular}

\section{Combustor}

The fuel delivery and combustion process is modeled by a $40-\mathrm{ms}$ transport delay, in conjunction with a slight flow resistance due to losses at the liner and mixer. The model of the heat release process is simplified by assuming that the combustion process is stoichiometric (i.e. no unburned hydrocarbons remain).

\section{Turbines}

As with the compressors, the turbines are represented by maps relating shaft speed to $\varphi$ and $\eta$, however since the relationship between $P R$ and $\varphi$ is unique, $P R$ is used as the other independent variable (in addition to shaft speed) for indexing the maps. The energy of the gas flow produces work on the shaft, thereby driving the associated fan and compressors. In the HPT and LPT, the cooling bleed flows re-enter the gas stream with a substantial pressure drop due to the cooling passages through which they pass. The map characteristics at the design point for the HPT and LPT are given in table 1.

\section{Nozzles}

The core and bypass nozzles are modeled as adiabatic expansion processes. The core and bypass are subsonic in nature, which calls for a converging nozzle design. Standard subsonic compressible flow relationships are used to represent the expansion process. 


\section{Shaft Dynamics}

The fan and core shaft dynamics are governed by the conservation angular momentum, where the sum of the shaft torques is proportional to the angular acceleration (derivative of the shaft speed, or Ndot). The lumped shaft inertia governs the acceleration and deceleration of the shaft. The moments of inertia for the low- and high-speed rotors are 533 and $47.7 \mathrm{ft}-1 \mathrm{~b}-\mathrm{s}^{2}$, respectively.

\section{Duct Losses}

At the exit of each component, a small pressure drop is inserted to represent the frictional losses due to the duct walls lumped at a discrete location.

\section{Variable Bleed Valve}

The primary purpose of the VBV is to avoid compressor instability, namely to prevent the compressor from entering stall at an operating condition. As stated above, bleeds are usually modeled as fractional flow extractions from the primary flow. The VBV is capable of actuating a large percentage of the core flow to the bypass duct and must also modulate the flow path at moderate to high power settings, meaning that the flow will be choked under certain conditions. For this reason, the VBV cannot be modeled as a proportional orifice, and is instead modeled using isentropic compressible flow principles, under the assumption of ideal converging-diverging nozzle flow.

\section{Variable Stator Vanes}

The VSV are typically located at the forward stages of the HPC and are used as a means to maintain compressor stability and prevent choking of the downstream compressor stages. In the HPC, the VSV effects have been represented by nonlinear modifications to the baseline component maps. The HPC maps were generated with the stator vanes operating on a control schedule; therefore the delta values from this

schedule have been approximated from compressor data that is a function of corrected core speed $N_{2}^{R}$ and vane angle. The compressor $P R, \varphi$ and $\eta$ maps are thus formulated in terms of elemental maps of flow coefficient, isentropic work and actual work. With this representation, the effects of the VSV angle have a multiplicative (scalar) influence and are easily incorporated.

\section{Stall Margin}

Stall margins ( $S M_{\mathrm{Fan}}, S M_{\mathrm{LPC}}, S M_{\mathrm{HPC}}$ ) are computed by comparing the actual pressure ratio to the pressure ratio at the stall line for the same corrected flow rate. On a compressor map, this is geometrically visualized as the vertical difference between the current operating point and the stall line.

\section{Health Parameters}

Health parameters are useful adjustments to a simulation for representation of damage, deterioration, or a fault condition. In gas-path health-management research, these parameters are essential for studying detection and/or isolation of faults or deterioration. As shown in table 2, there are 13 health parameters, each corresponding to an adjustment to the map parameters in a rotating component. In the fan and each of the compressor routines, there are three health parameters corresponding to a percent corrected flow rate, pressure ratio, or efficiency "delta" relative to the nominal value. Degradation can be approximated by incorporating a steady-state adjustment to the health parameters; a fault can be simulated by imposing a time-dependent shift in the health parameter, by specifying the time-dependent profile that characterizes the fault. 
TABLE 2.-HEALTH PARAMETERS

\begin{tabular}{|l|l|l|}
\hline & Parameter & Description \\
\hline 1 & $\eta_{\text {mod,Fan }}$ & Fan efficiency modifier \\
2 & $\varphi_{\text {mod,Fan }}$ & Fan corrected flow modifier \\
3 & $P R_{\text {mod,Fan }}$ & Fan pressure ratio modifier \\
\hline 4 & $\eta_{\text {mod,LPC }}$ & LPC efficiency modifier \\
5 & $\varphi_{\text {mod,LPC }}$ & LPC corrected flow modifier \\
6 & $P R_{\text {mod,LPC }}$ & LPC pressure ratio modifier \\
\hline 7 & $\eta_{\text {mod,HPC }}$ & HPC efficiency modifier \\
8 & $\varphi_{\text {mod,HPC }}$ & HPC corrected flow modifier \\
9 & $P R_{\text {mod,HPC }}$ & HPC pressure ratio modifier \\
\hline 10 & $\eta_{\text {mod,HPT }}$ & HPT efficiency modifier \\
11 & $\varphi_{\text {mod,HPT }}$ & HPT corrected flow modifier \\
\hline 12 & $\eta_{\text {mod,LPT }}$ & LPT efficiency modifier \\
13 & $\varphi_{\text {mod,LPT }}$ & LPT corrected flow modifier \\
\hline
\end{tabular}

\section{Actuator and Sensor Dynamics}

The dynamics of several actuators and sensors have been included in the simulation. The fuel metering valve (FMV) actuator, along with the VSV and VBV servoactuators have been modeled by simple first-order transfer functions, which is a valid approach to use for sample rates as slow as the controller rate. For the VBV and VSV, the actuator commands are open-loop scheduled on corrected fan and core speeds, respectively. The bleed valve is scheduled such that the valve is fully open at low power and closed at moderate-to-high power settings. The variable stators are commanded a positive deflection $\left(50^{\circ}\right)$ at low power and move to zero deflection at high settings. As with the actuators, the sensors are also taken as first-order lags, whose bandwidth parameters are given in table 3.

TABLE 3.-ACTUATOR AND SENSOR
\begin{tabular}{|c|l|r|}
\hline DESCRIPTIONS AND BANDWIDTHS \\
\hline$W f$ & \multicolumn{1}{|c|}{ Description } & Bandwidth \\
\hline$V B V$ & Variable bleed valve & $25 \mathrm{rad} / \mathrm{s}$ \\
$V S V$ & Variable stator vanes & $23 \mathrm{rad} / \mathrm{s}$ \\
$N_{1}$ & Fan speed & $23 \mathrm{rad} / \mathrm{s}$ \\
$N_{2}$ & Core speed & $50 \mathrm{rad} / \mathrm{s}$ \\
$T_{20}$ & Fan inlet temperature & $50 \mathrm{rad} / \mathrm{s}$ \\
$P_{20}$ & Fan inlet pressure & $9 \mathrm{rad} / \mathrm{s}$ \\
$T_{24}$ & LPC outlet temperature & $25 \mathrm{rad} / \mathrm{s}$ \\
$P s_{30}$ & Combustor static pressure & $9 \mathrm{rad} / \mathrm{s}$ \\
$T_{48}$ & HPT exhaust gas temp. & $25 \mathrm{rad} / \mathrm{s}$ \\
$P_{50}$ & Core exhaust pressure & $9 \mathrm{rad} / \mathrm{s}$ \\
\end{tabular}

It should be evident at this point that the physical engine system represented here is fairly comprehensive in scope. Although three-dimensional flow effects have been eliminated, the effects of heat soakage and tip clearance have not been incorporated, and some simplifying assumptions have been made, the gross aero-thermodynamic effects remain intact. As such, the resulting model is useful for examining important gas-path-related effects of interest for control law or health management system developers.

\section{B. The Engine Balance Solver Routine}

The engine has two physical state variables: fan speed and core speed (with respective time constants governed by rotor inertia). The fan, two compressors and two turbines each possess one unknown variable: for the fan and compressors this is the $R$-line value, for the turbines it is pressure ratio. An 
iterative solver is used to drive down the flow continuity errors between each of the five major components in order to uniquely solve the five unknowns. Although it is more accurate to iterate until a tolerance is reached, the solver is set up to execute only once per sample (every $0.015 \mathrm{~s}$ ) to improve the execution speed of C-MAPSS.

Due to the two-way coupling that exists between the spool speeds and the thermodynamic processes, the system can be balanced on the basis of the aero-thermodynamic principles. In reality, each component has its own gas volume storage, and this compliance creates a lag between components that allows the solution to be described by these dynamics directly without a dedicated solver. However, the volume dynamics are at a bandwidth far greater than the controller sample rate (by more than an order of magnitude; time constants are typically less than $1 \mathrm{~ms}$ ). This would require the simulation to operate much faster than the controller rate, to the detriment of execution speed, and is hence not employed here.

Since the spool dynamics are slower than the controller dynamics, the closed loop system is operated at the controller $67 \mathrm{~Hz}$ update rate $(0.015 \mathrm{~s}$ period) and an iterative solver used to balance the engine at this discrete update rate. The solver is based on a Newton-Raphson scheme using a static Jacobian matrix $J$ obtained at a single operating point. The errors are driven toward zero through the following difference equation

$$
x_{k+1}=x_{k}-J^{-1} e_{k}
$$

where $e_{k}$ is an error vector of the same dimension as the vector of independent parameters $x_{k}$. The error parameters are each taken to establish flow continuity between components (flow exiting a component equals the flow entering the next component, minus any bleeds). In the turbines, the independent parameters are taken simply as the pressure ratios, while in the fan and compressors these are taken as the $R$-line values. A listing of the five flow continuity errors and the five independent parameters is given in table 4. Even using the fixed-Jacobian single-iteration solver, the flow continuity errors remain within 15 percent at worst (continuity of flow across the HPC) for a typical large-magnitude burst transient. This is due in part to the controller limiting the speed of the engine. Although these errors may be undesirable for detailed performance studies, for most controls and diagnostics studies, this approach should prove to be sufficient.

TABLE 4.-COMPRESSOR/TURBINE SOLVER PARAMETERS

$\left[W_{i}\right.$ represents mass flow at station $i$.]

\begin{tabular}{|l|l|l|}
\hline & \multicolumn{1}{|c|}{$\begin{array}{c}\text { Flow continuity } \\
\text { error quantity }\end{array}$} & \multicolumn{1}{|c|}{$\begin{array}{c}\text { Independent } \\
\text { parameter }\end{array}$} \\
\hline 1 & $W_{21}-W_{13}-W_{24}$ & $R$-line $e_{\text {Fan }}$ \\
\hline 2 & $W_{24}-W_{30}$ & $R$-line $e_{\mathrm{LPC}}$ \\
\hline 3 & $W_{48}-W_{40}-W_{\mathrm{HPTbld}, 1}-W_{\mathrm{HPTbld}, 2}$ & $R$-line HPC $_{\mathrm{HP}}$ \\
\hline 4 & $W_{50}-W_{48}-W_{\mathrm{LPTbld}, 1}-W_{\mathrm{LPTbld}, 2}$ & $P R_{\mathrm{HPT}}$ \\
\hline 5 & $W_{50}-W_{90}$ & $P R_{\mathrm{LPT}}$ \\
\hline
\end{tabular}

\section{Control System}

The default control system that is provided with C-MAPSS is a gain-scheduled linear control law with a simplified limit protection scheme, which is representative of the state-of-the-art in digital engine control systems employed by industry. The specifics of engine control systems are proprietary, so details of the actual limit schedules, controller time constants, and mode selection thresholds have been constructed based on knowledge of the safety, stability, and operability margins of the C-MAPSS engine.

The comprehensive control system consists of a fan-speed compensator, four limit regulators, and core speed acceleration and deceleration limiters. Three high-limit regulators prevent the engine from exceeding its design limits for core speed $\left(N_{2}\right)$, combustor static pressure $\left(P_{S_{30}}\right)$, and HPT exit temperature. The core speed limit is designed to prevent mechanical failure of the rotating components, 


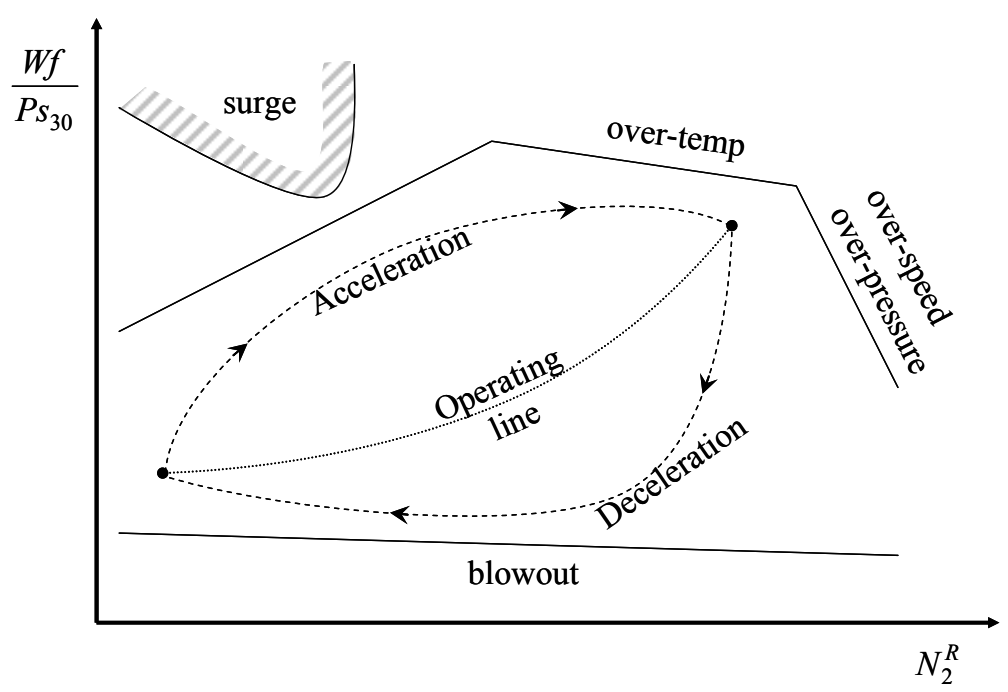

Figure 2.--Illustration of the limit protection philosophy.

while engine pressure ratio and temperature limits are set up to prevent failure of the high pressure and high temperature components. A fourth limit regulator is instituted to prevent the static pressure at the exit of the HPC from going too low to prevent lean combustor blowout. The operation of the control limits is illustrated in figure 2 .

As shown in figure 2, acceleration and deceleration limits are implemented primarily to prevent compressor stall during transients. Secondarily, the acceleration limit is an additional measure to prevent over-stress of the rotor and the deceleration protects against blowout. As is common among manufacturers (ref. 12), the variable $\Phi=W f / P s_{30}$ is used to prevent stall; the maximum $\Phi$ is set to prevent HPC stall and the minimum is set to prevent LPC stall. This is because the HPC stall margin experiences undershoot as compressor through-flow increases, while the LPC stall margin experiences its undershoot as the through-flow decreases. In C-MAPSS, margins are maintained at 15 percent in the HPC and 6 percent in the LPC. The minimum and maximum values of $\Phi$ are determined to maintain these margins as $N_{2}^{R}$ varies. This control limit differs from the four limit regulators in that the fuel flow is saturated (by setting the derivative to zero) when acceleration or deceleration exceeds tolerance. To calculate the minimum and maximum $W f$ limits, the minimum and maximum values of $\Phi$ are scheduled against $N_{2}^{R}$ and are multiplied by $P_{30}$. As will be shown, the fuel flow derivative is accessible for the saturation limit since it is the controlled variable.

The fan speed regulator and limit regulators are designed using the model-matching (MM) method, formalized by Edmunds (ref. 13). With this technique, the desired closed-loop transfer function and the compensator poles are specified and the compensator's gain and zeros are obtained to provide the best match to the desired transfer function in a least-squares sense. The gain and feedthrough matrices of the fan speed regulator are scheduled versus $N_{2}^{R}$ and $P_{20}$. The $P_{20}$ schedule is necessary to consolidate the effects of altitude and Mach number variations into one parameter. Each of the limit regulators consists of static parameters designed at a representative flight condition consistent with the limit.

In actual FADEC control systems, extensive provisions are made in the logic structure to avoid integrator-windup problems and ensure smooth, chatter-free transition between control modes. The C-MAPSS controller emulates these provisions by incorporating an incremental control command and interpolating the scheduled linear gains that discretize the entire flight envelope. With the plant augmented with a free integrator, the second-order MM regulators are referred to as "incremental" (rate) regulators. To prevent integrator windup, only one free integrator is required for all control modes since only one is active at any time. Therefore, all control modes operate on the control derivative, instead of the absolute (integrated) signal. 


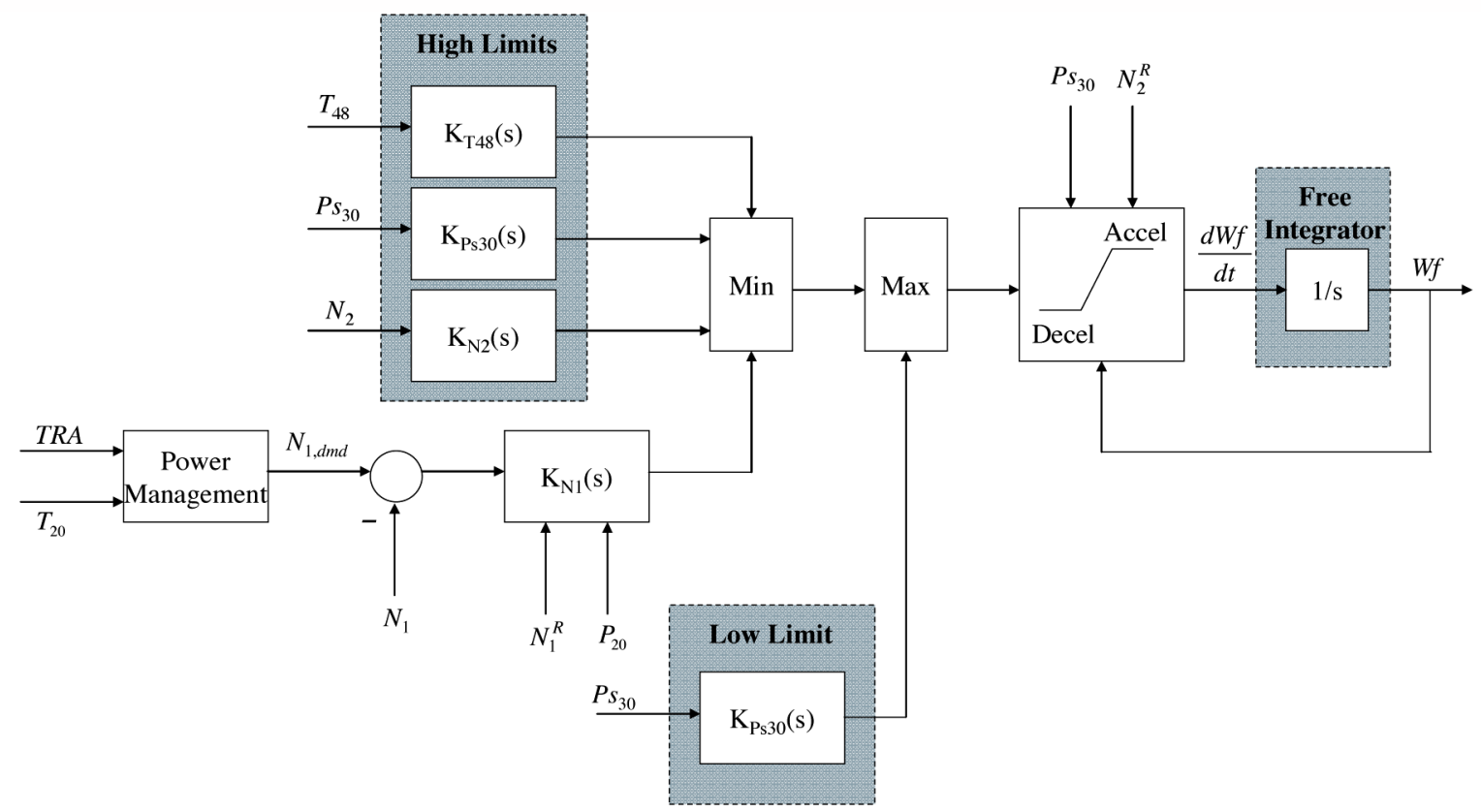

Figure 3.-Fuel flow control logic. Inputs refer to the sensor measurements and the output is the fuel flow command.

A power management system has been included in order to relate the pilot's TRA (throttle resolver angle) input to a demanded corrected fan speed. In order to approximate a linear TRA-to-net thrust relationship, a table lookup is used whose profile is such that the sensitivity of $N_{1}^{R}$ to TRA increases as TRA increases. By correcting fan speed with respect to $T_{20}$, it allows the engine to be operated over a wide range of thrust levels throughout the full range of flight conditions. Figure 3 depicts the complete fuel flow control architecture.

\section{The C-MAPSS Program User Interface and Operation}

The C-MAPSS program consists of Matlab code, a GUI, and Simulink diagrams which appear to the user as shown in figures 4 and 5. Note the user-specified flight condition down the center of the GUI (fig. 4) and the user-selected profiles of the three control inputs (TRA, VSV and VBV) and the three environmental parameters (altitude, Mach number, and delta ambient temperature) on the right side of the GUI. The GUI is structured to facilitate the following basic tasks: generation of flight conditions and input profiles; construction of linear models; design of engine controllers and limit regulators via the MM method; execution of open-/closed-loop simulations and examination of the results. Thus the user is able to perform several practical functions through a point-and-click approach using the menu picks along the top of the GUI. Each GUI task is carried out via a Simulink representation of the C-MAPSS engine (fig. 5) that is configured appropriately. This section details the various features of the C-MAPSS user interface and provides a simple example to demonstrate the operability of the simulation. 


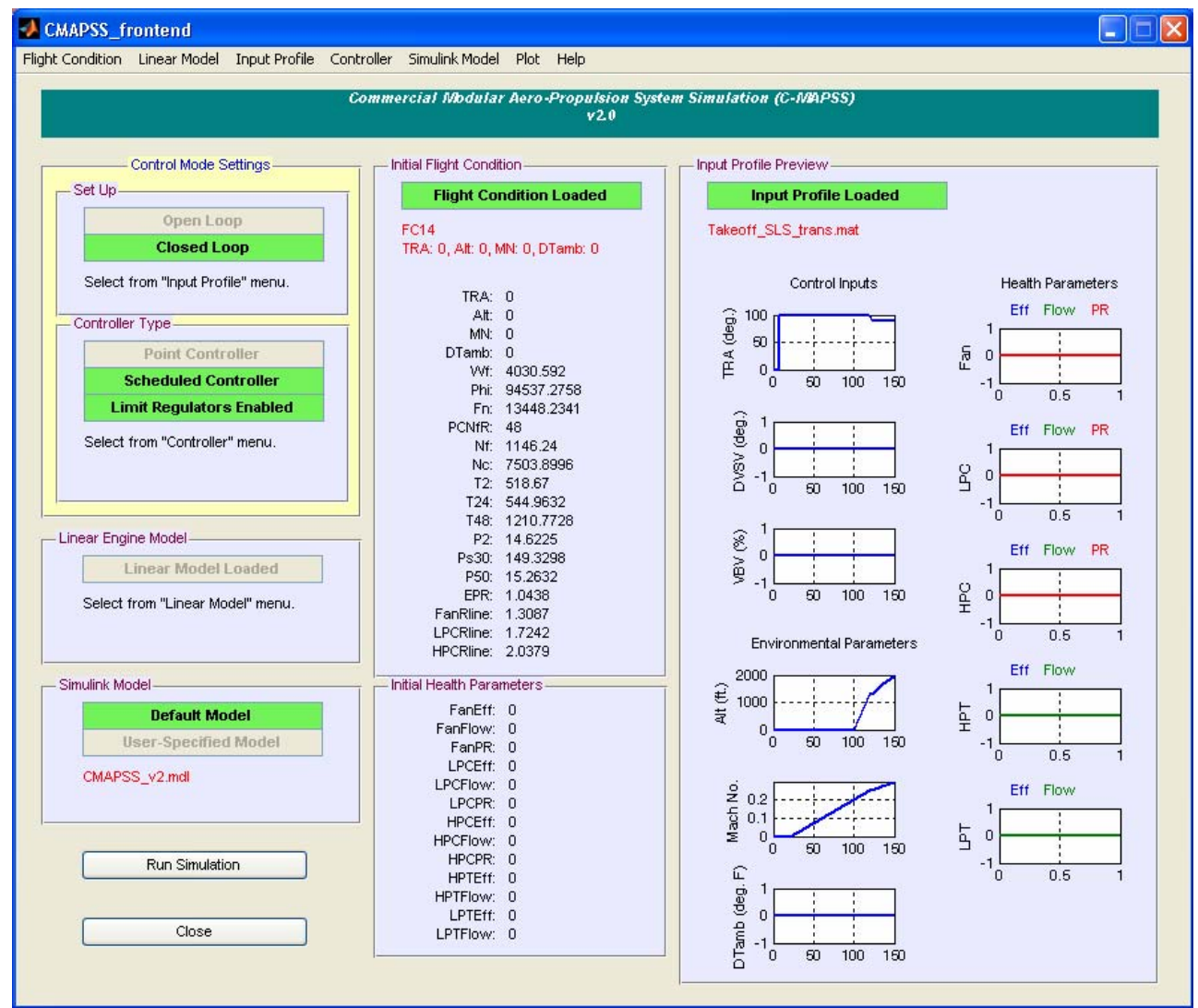

Figure 4.-Front-end GUI of C-MAPSS, for setting up and running the simulation.

\section{Commercial Modular Aero-Propulsion System Simulation (C-MAPSS)}

(ver. 2.0)

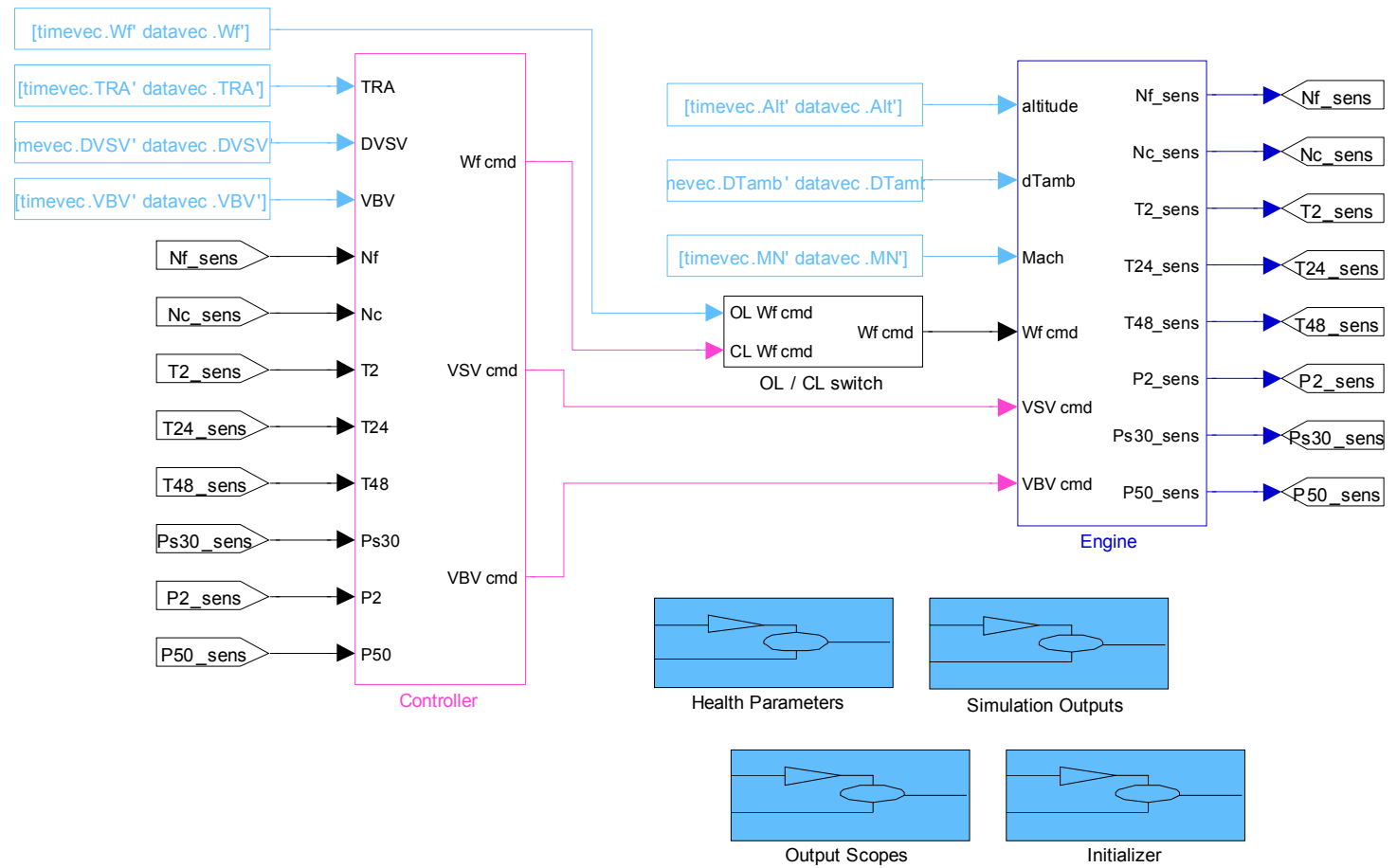

Figure 5.-Top-level Simulink diagram. 


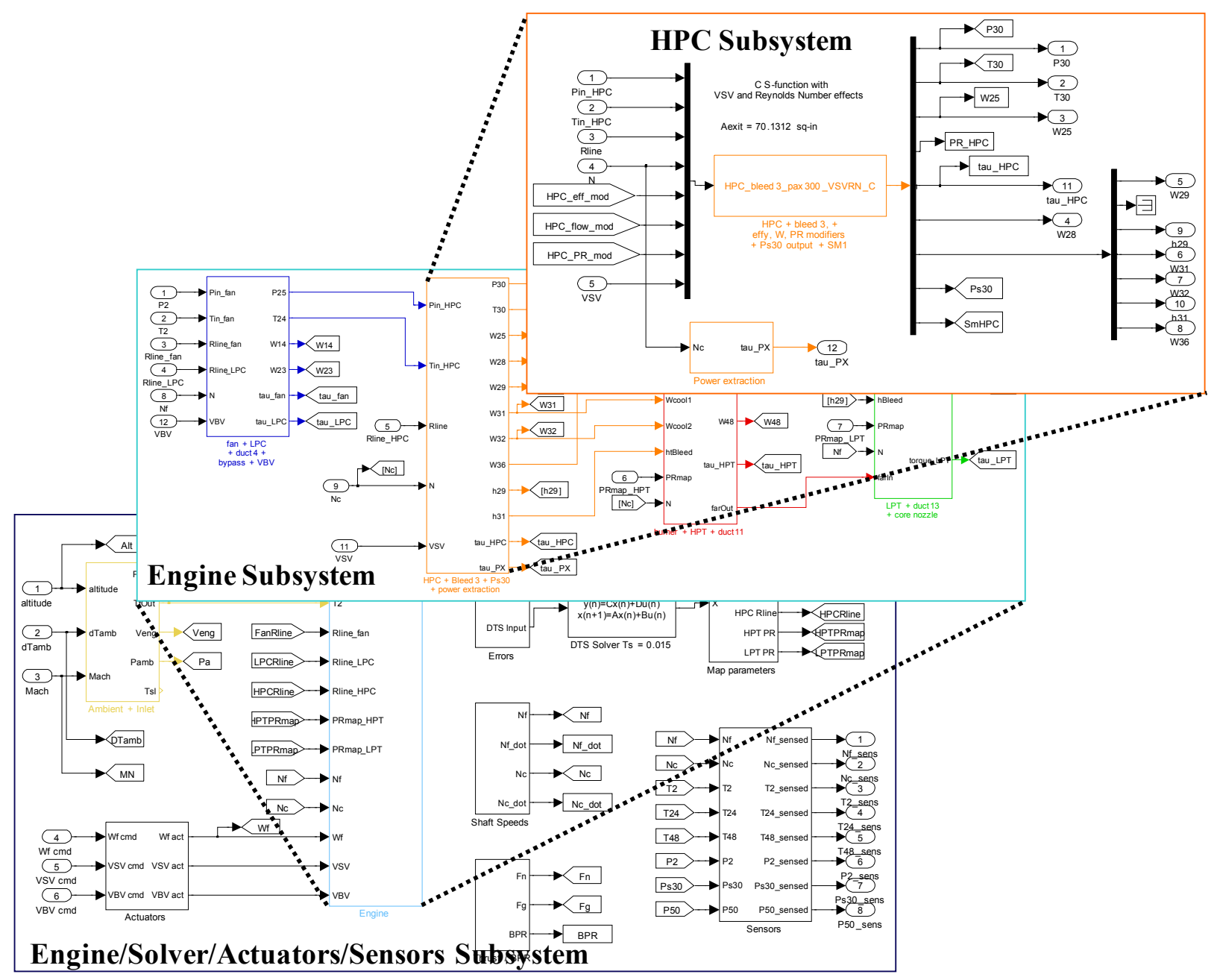

Figure 6.-IIlustration of C-MAPSS subsystem hierarchy.

\section{A. Implementation and Use}

The engine-level subsystem is shown in figure 6, which is the subsystem that contains the solver, shaft dynamics, sensors, actuators, atmospheric model, and engine aero-thermodynamic model. At the lowest level of the Simulink hierarchy, the aero-thermodynamic model is comprised of s-functions that represent the engine's major components. The inputs and outputs of the 10 major components and the design characteristics for each are given in table 5. In the table, note that the Fan exit flow is split between the bypass duct and the LPC inlet. As a result of the split, it should be clear that the pressures, temperatures, and flows are related by $P_{21}=P_{13}=P_{22}, T_{21}=T_{13}=T_{22}$, and $W_{21}=W_{13}+W_{22}$. 
TABLE 5.-MAJOR COMPONENT MODULES FOR C-MAPSS,

ALONG WITH THEIR INPUTS AND OUTPUTS

[Fg, h, FAR and $\tau$ represent gross thrust, enthalpy, fuel-to-air ratio, and torque, respectively.]

\begin{tabular}{|c|c|c|}
\hline Component & $\begin{array}{l}\text { s-function } \\
\text { inputs }\end{array}$ & $\begin{array}{c}\text { s-function } \\
\text { outputs }\end{array}$ \\
\hline Inlet & $T_{10}, P_{10}, M N$ & $T_{20}, P_{20}$ \\
\hline Fan & $\begin{array}{l}T_{20}, P_{20}, N_{1}, R \text {-line } \text { Fan }_{\text {Fan }} \\
\eta_{\text {mod,Fan }}, \varphi_{\text {mod,Fan }}, P R_{\text {mod,Fan }}\end{array}$ & $T_{21}, P_{21}, W_{21}, \tau_{\text {Fan }}, S M_{\text {Fan }}$ \\
\hline Bypass Nozzle & $T_{13}, P_{13}, P_{\mathrm{amb}}, W_{\mathrm{VBV}}$ & $W_{13}, F g_{\text {Byp }}$ \\
\hline $\begin{array}{l}\text { Low Pressure } \\
\text { Compressor }\end{array}$ & $\begin{array}{l}T_{22}, P_{22}, N_{1}, R \text {-line } \text { LPC }_{\text {L }} \\
\eta_{\text {mod,LPC }}, \varphi_{\text {mod,LPC }}, P R_{\text {mod,LPC }}\end{array}$ & $T_{24}, P_{24}, W_{24}, \tau_{\mathrm{LPC}}, S M_{\mathrm{LPC}}$ \\
\hline Variable Bleed & $V B V, T_{24}, P_{24}, W_{24}, T_{13}, P_{13}, W_{13}$ & $W_{\mathrm{VBV}}$ \\
\hline $\begin{array}{l}\text { High Pressure } \\
\text { Compressor }\end{array}$ & $\begin{array}{l}T_{25}, P_{25}, W_{\mathrm{VBV}}, N_{2}, R \text {-line } \text { HPC }_{\mathrm{HP}}, V S V \\
\eta_{\text {mod,HPC }}, \varphi_{\text {mod,HPC }}, P R_{\text {mod,HPC }}\end{array}$ & $\begin{array}{l}T_{30}, P_{30}, P S_{30}, W_{25}, W_{36}, \tau_{\mathrm{HPC}}, S M_{25} \\
h_{\text {LPTbld }}, W_{\text {LPTbld }, 1}, W_{\text {LPTbld, } 2}, W_{\text {Cust_bld }} \\
h_{\text {HPTbld }}, W_{\text {HPTbld }, 1}, W_{\text {HPTbld }, 2}\end{array}$ \\
\hline Combustor & $T_{30}, P_{30}, W_{36}, W f$ & $T_{40}, P_{40}, W_{40}, F A R_{40}$ \\
\hline $\begin{array}{l}\text { High Pressure } \\
\text { Turbine }\end{array}$ & $\begin{array}{l}T_{40}, P_{40}, F A R_{40}, N_{2}, P R_{\mathrm{HPT}} \\
h_{\mathrm{HPTbld}}, W_{\mathrm{HPTbld}, 1}, W_{\mathrm{HPTbld}, 2} \\
\eta_{\text {mod,HPT }}, \varphi_{\text {mod,HPT }}\end{array}$ & $T_{48}, P_{48}, W_{48}, F A R_{48}, \tau_{\mathrm{HPT}}$ \\
\hline $\begin{array}{l}\text { Low Pressure } \\
\text { Turbine }\end{array}$ & $\begin{array}{l}T_{48}, P_{48}, F A R_{48}, N_{1}, P R_{\mathrm{LPT}} \\
h_{\mathrm{LPTbld}}, W_{\mathrm{LPTbld}, 1}, W_{\mathrm{LPTbld}, 2} \\
\eta_{\text {mod,LPT }}, \varphi_{\text {mod }, \mathrm{LPT}}\end{array}$ & $T_{50}, P_{50}, W_{50}, F A R_{50}, \tau_{\mathrm{LPT}}$ \\
\hline Core Nozzle & $T_{50}, P_{50}, P_{\mathrm{amb}}, F A R_{50}$ & $W_{90}, F g_{\text {Core }}$ \\
\hline
\end{tabular}

At this point, it is worth noting how the s-functions are composed. Because there are certain advantages and disadvantages of Matlab-based and C-based s-functions, each component has been coded in both formats. In short, the Matlab functions are useful for editing the module without needing to reprogram and recompile the s-function code, but tend to have long execution times. The $\mathrm{C}$ functions, while more complicated to implement, allow the full simulation to be executed much more quickly (about seven times faster than real time on a standard desktop equipped with a $2.2 \mathrm{GHz}$ processor).

The C-MAPSS user interface environment is now discussed in greater detail. As has been stated, each of the automated functions is accessible from the front-end GUI, which is powered in the background by Matlab scripts and the main Simulink file. The various functions are accessed by the menu options at the top of the GUI.

\section{Initialization}

The simulation is initialized by simply balancing the engine to equilibrium for a prescribed set of inputs (flight, power setting, and deterioration conditions). The speed of convergence is expedited by removing the controller and engine dynamics and replacing these with an augmented, eight-state NewtonRaphson solver. The errors in this case include the five continuity errors, the net torques on the two shafts, and the controlled variable. In open-loop, the controlled variable is fuel flow, while in closed-loop, this may be chosen as either TRA or net thrust in the GUI. As with the standard five-state discrete-time solver, the engine balancing solver operates with a static Jacobian matrix to rapidly solve for the independent variables. Unlike the standard solver, however, limits are treated by swapping rows of the Jacobian matrix corresponding to the limited/un-limited output variable. Implementation-wise, once a limit is reached, the output variable to be controlled is switched to this limited variable, and an inverse Jacobian corresponding to that variable is selected. The balancing proceeds until the root-mean-square (rms) error falls below a certain user-specified threshold.

\section{Input Profiles}

In normal, undegraded operation, the input profile is specified by the three environmental variables (altitude, MN, and delta ambient temperature), the two variable geometry actuator inputs (VSV, VBV), and either fuel flow or TRA, depending on whether the intent is to perform open-loop or closed-loop 
simulations. Time-indexed vectors for each of these inputs are specified by either loading an existing profile (e.g., takeoff, climb, descent) or constructing a new step or ramp profile in the Input Profile GUI. The GUI simply facilitates the task of constructing data vectors that are called by the simulation from the Matlab workspace.

\section{Linearization}

The open-loop engine may be linearized at any arbitrary flight condition for controls and diagnostics development. The Linear Engine Model GUI facilitates the process by performing the linearization with user-specified perturbation magnitudes on each state and input variable. Once generated, the response of the linear model to an input perturbation may then be compared visually to that of the nonlinear model by making use of the preconfigured plotting routines within C-MAPSS.

\section{Control System}

The simulation can be configured to operate open-loop or in one of several closed-loop modes. When simulating in closed-loop, the user can choose to employ a linear point fan speed controller, a gainscheduled controller without limit regulators, or a gain-scheduled controller with all limits activated. Although a comprehensive set of point controllers has been included with C-MAPSS, users may choose to design point compensators of their own. Once a linear model has been generated, the Controller Design GUI allows the user to rapidly perform the MM design at that flight condition and conduct loop analysis of the compensator design. Of course, the user is free to substitute a customized controller for the standard one by simply replacing the contents of the "Controller" Simulink block with a subsystem containing the new algorithm.

\section{Degraded Operation}

Abrupt faults or gradual degradation in the engine can be approximated by use of the health parameter inputs. As with the open-/closed-loop command inputs, this is done by specifying an appropriate time history for any of the 13 health parameter inputs as time vectors in the Matlab workspace or via the Input Profile GUI, where a step or ramp transient may be constructed. The reader is referred to other sources for information on possible settings for simulating deterioration (ref. 14) and faults (ref. 15).

\section{B. Closed-Loop Example}

Some illustrative results of the engine simulation are shown in figures 7 and 8 . The test case shown is for a burst/chop throttle maneuver between $0^{\circ}$ and $100^{\circ}$ TRA conducted at sea-level static, standard day conditions. The example illustrates that the fan-speed compensator (in control the majority of the time) produces a smooth fan speed response that does not violate any limits. The VBV and VSV actuators follow schedules that are inversely related to the corrected fan and core speeds, respectively. The only limiter that comes into play is the $\Phi\left(W f / P S_{30}\right)$ saturation limit; the maximum is encountered during burst and the minimum encountered during chop. Figure 8 shows the transient response of the stall margins in the fan and compressor components. Viewed on the pressure ratio map, the fan stall margin evolves within a narrow region and hence does not require limit protection. The LPC and HPC, on the other hand, both have large-magnitude transient responses that require protection by the $\Phi$ limit. By virtue of their design, the limits prevent the LPC stall margin from falling below 6 percent during chop and the HPC stall margin from falling below 15 percent during burst. 

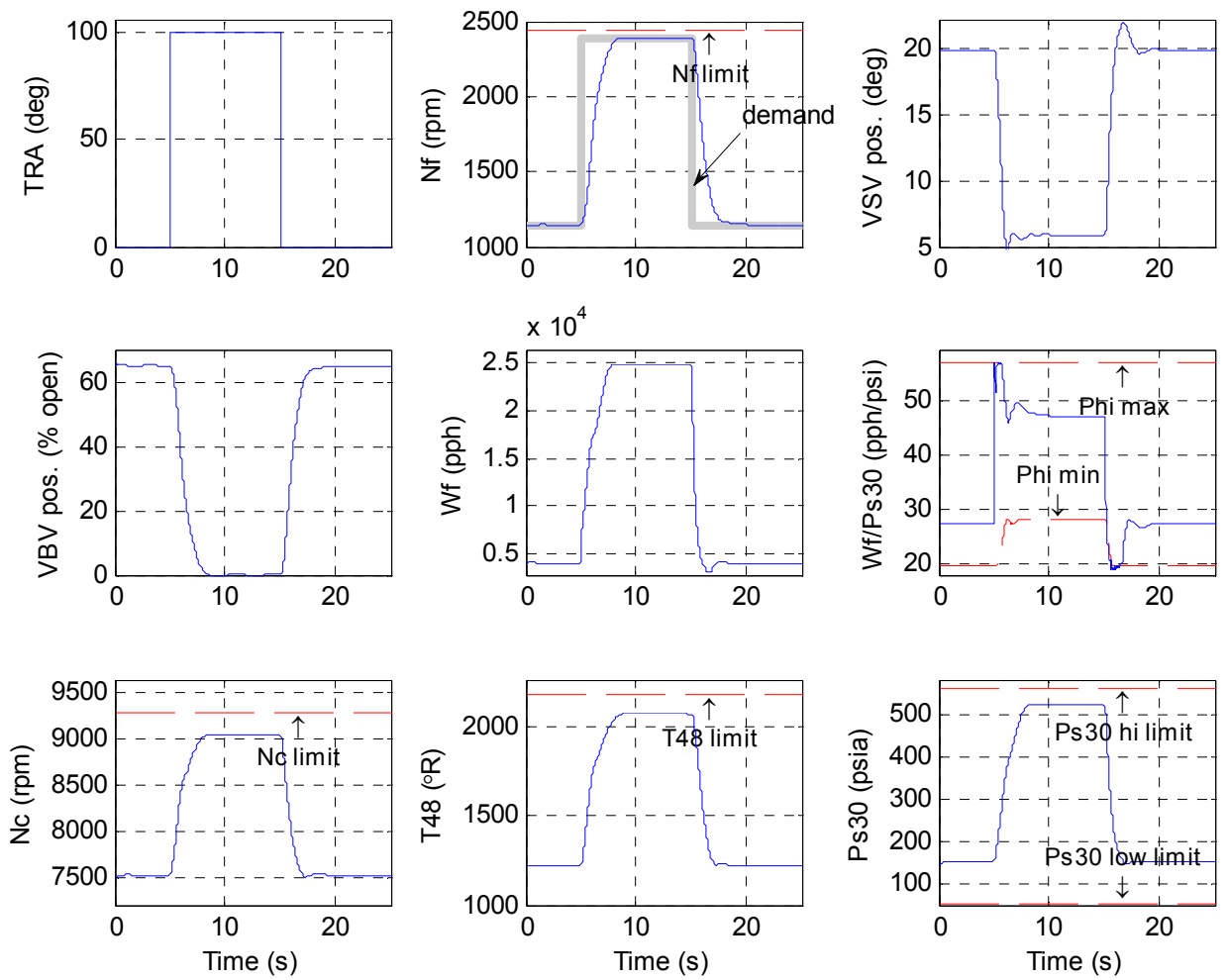

Figure 7.-Time traces for a burst followed by a chop at sea-level static conditions.
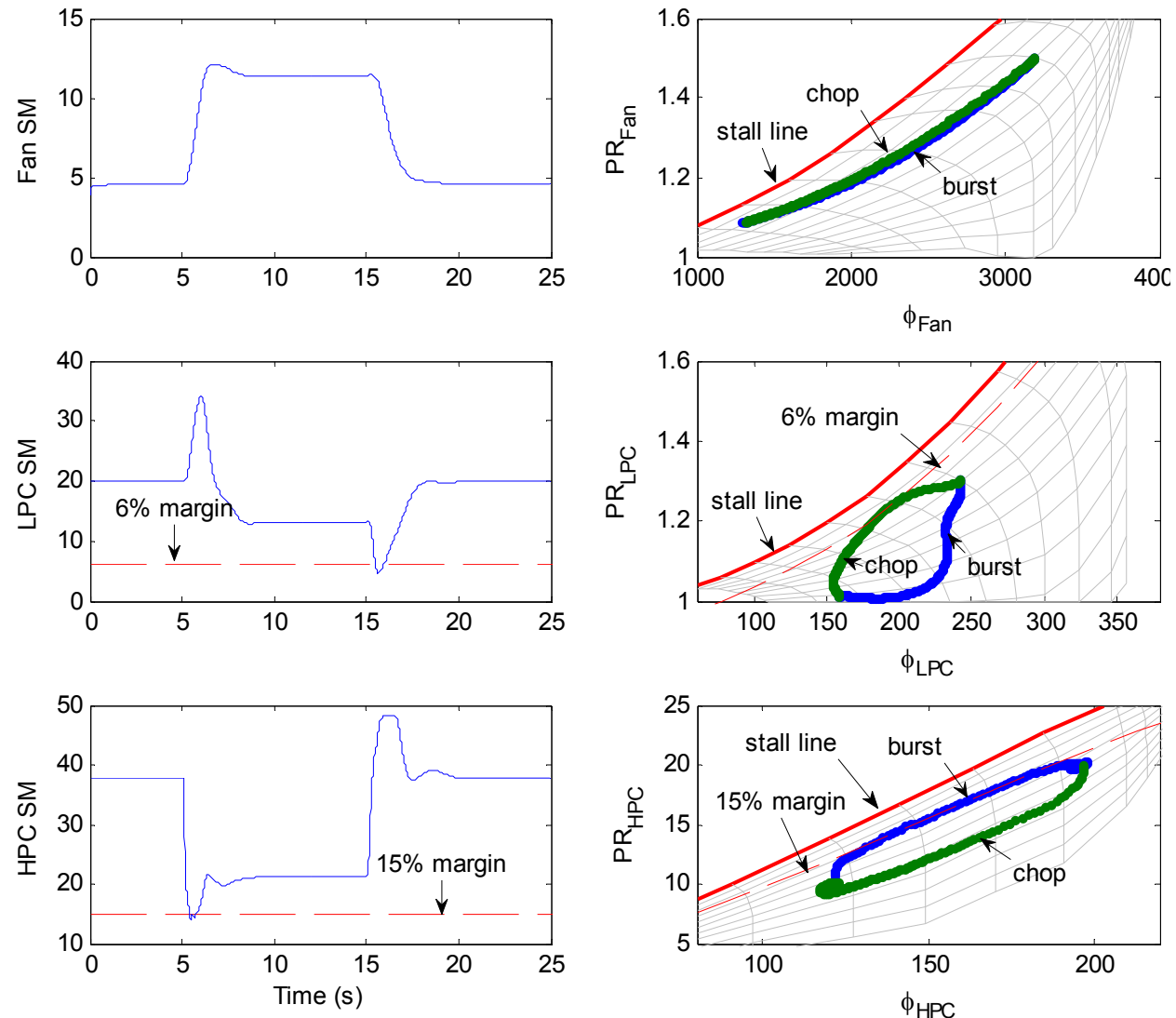

Figure 8.-Burst/chop trajectories shown in relation to the fan, LPC, and HPC pressure ratio versus corrected flow maps. 


\section{Summary}

This paper presents an overview of the construction and implementation of the Commercial Modular Aero-Propulsion System Simulation (C-MAPSS) version 2 engine simulation. The basic elements of the aero-thermodynamic model have been discussed, as have the details relating to the solver and controller. The open-loop engine model has been constructed to provide comprehensive detail for each of the components and such that all of the relevant control "handles" and sensors that are of interest to users in the engine controls and diagnostics/health management community are provided. The controller has been essentially designed to represent modern digital control laws in a simplified, easily understood fashion. To that end, the controller consists of a gain-scheduled fan speed controller with associated limit logic to prevent the normal over-speed, over-temperature, over-pressure, compressor stall and lean blowout conditions. Due to C-MAPSS' modular structure, a user-developed control law can be easily substituted for the existing one. In an effort to simplify common tasks, several simulation functions have been automated through the GUI environment. These include initialization of the engine at an arbitrary point, creation of linear models and point controllers, and generation of responses to various input profiles. The various engine components were implemented as Matlab s-functions to facilitate building and refining each of those modules. To promote fast simulations and to provide opportunity for real-time implementation, the modules were also deployed as $\mathrm{C}$ language-based s-functions. As a result of the steps taken to construct the simulation, C-MAPSS is a versatile tool that offers a wide array of functionality.

\section{References}

1. Parker, K.I. and Guo, T.H., "Development of a Turbofan Engine Simulation in a Graphical Simulation Environment," NASA/TM-2003-212543, August 2003.

2. Kim, J.H., Song, T.W., Kim, T.S. and Ro, S.T., "Model Development and Simulation of Transient Behavior of Heavy Duty Gas Turbines," J. Engineering for Gas Turbines and Power, vol. 123, no. 3, 2001, pp. 589-594.

3. Alexiou, A. and Mathioudakis, K., "Development of a Turbofan Performance Model Using a Generic Simulation Tool," 2005 ASME Turbo Expo, Reno-Tahoe, NV, June 6-9, 2005.

4. Camporeale, S.M., Fortunato, B. and Mastrovito, M., "A Modular Code for Real Time Dynamic Simulation of Gas Turbines in Simulink," J. Engineering for Gas Turbines and Power, vol. 128, no. 3, 2006, pp. 506-517.

5. Mink G., and Behbahani, A., "The AFRL ICF Generic Gas Turbine Engine Model,” AIAA-20054538, 41st AIAA/ASME/SAE/ASEE Joint Propulsion Conference and Exhibit, Tucson, AZ, July 10 13, 2005.

6. Frederick, D.K., DeCastro, J.A. and Litt, J.S., "User's Guide for the Commercial Modular AeroPropulsion System Simulation (C-MAPSS)," NASA/TM-2007-215026, October 2007.

7. Mattingly, J.D., Elements of Gas Turbine Propulsion, McGraw-Hill, 1996.

8. Seldner, K., Mihaloew, J.R. and Blaha, R.J., "Generalized Simulation Technique for Turbojet Engine System Analysis," NASA TN D-6610, February 1972.

9. Kulikov, G.G. and Thompson, H.A. (eds.), Dynamic Modelling of Gas Turbines: Identification, Simulation, Condition Monitoring, and Optimal Control, Springer-Verlag, London, 2004.

10. Spang III, H.A. and Brown, H., "Control of Jet Engines," Control Engineering Practice, vol. 7, no. 9, 1999, pp. 1043-1059.

11. Volponi, A.J., "Gas Turbine Parameter Corrections," J. Engineering for Gas Turbines and Power, vol. 121, no. 4, pp. 613-621.

12. Martucci, A. and Volponi, A.J., "Fuzzy Fuel Flow Selection Logic for a Real Time Embedded Full Authority Digital Engine Control," J. Engineering for Gas Turbines and Power, vol. 125, no. 4, 2003, pp. 909-916.

13. Maciejowski, J.M., Multivariable Feedback Design, Addison-Wesley, 1989. 
14. Sallee, G.P., "Performance deterioration based on existing (historical) data; JT9D jet engine diagnostics program," NASA CR-135448, April 1978.

15. Ogaji, S.O.T., Sampath, S., Singh, R., and Probert, S.D., "Parameter Selection for Diagnosing a GasTurbine's Performance-Deterioration,” Applied Energy, 73, 2002, pp. 25-46. 


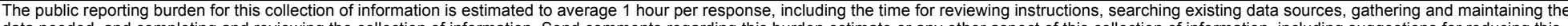

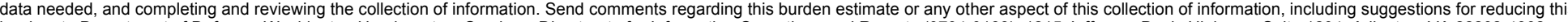

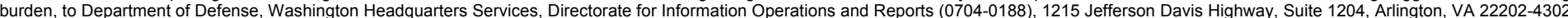

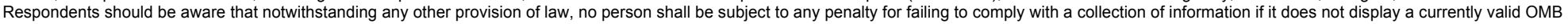
control number.

PLEASE DO NOT RETURN YOUR FORM TO THE ABOVE ADDRESS
1. REPORT DATE (DD-MM-YYYY)
2. REPORT TYPE
3. DATES COVERED (From - To)

01-09-2008

Technical Memorandum

\section{TITLE AND SUBTITLE}

A Modular Aero-Propulsion System Simulation of a Large Commercial Aircraft Engine

\section{5a. CONTRACT NUMBER}

5b. GRANT NUMBER

5c. PROGRAM ELEMENT NUMBER

6. AUTHOR(S)

DeCastro, Jonathan, A.; Litt, Jonathan, S.; Frederick, Dean, K.

\section{5d. PROJECT NUMBER}

5e. TASK NUMBER

5f. WORK UNIT NUMBER

WBS 457280.02.07.03.04.03

8. PERFORMING ORGANIZATION REPORT NUMBER

E-16573

National Aeronautics and Space Administration

John H. Glenn Research Center at Lewis Field

Cleveland, Ohio 44135-3191

\section{SPONSORING/MONITORING AGENCY NAME(S) AND ADDRESS(ES)}

National Aeronautics and Space Administration

Washington, DC 20546-0001

\section{DISTRIBUTION/AVAILABILITY STATEMENT}

Unclassified-Unlimited

Subject Category: 07

Available electronically at http://gltrs.grc.nasa.gov

This publication is available from the NASA Center for AeroSpace Information, 301-621-0390

\section{SUPPLEMENTARY NOTES}

\section{ABSTRACT}

A simulation of a commercial engine has been developed in a graphical environment to meet the increasing need across the controls and health management community for a common research and development platform. This paper describes the Commercial Modular Aero Propulsion System Simulation (C-MAPSS), which is representative of a 90,000-pound thrust class two spool, high bypass ratio commercial turbofan engine. A control law resembling the state-of-the-art onboard modern aircraft engines is included, consisting of a fan-speed control loop supplemented by relevant engine limit protection regulator loops. The objective of this paper is to provide a top-down overview of the complete engine simulation package.

15. SUBJECT TERMS

Simulation; Aircraft engines; Engine control; Thermodynamic cycles

\begin{tabular}{|c|c|c|c|}
\hline \multicolumn{3}{|c|}{ 16. SECURITY CLASSIFICATION OF: } & \multirow{2}{*}{$\begin{array}{l}\text { 17. LIMITATION OF } \\
\text { ABSTRACT } \\
\text { UU }\end{array}$} \\
\hline $\begin{array}{l}\text { a. REPORT } \\
\text { U }\end{array}$ & $\begin{array}{l}\text { b. ABSTRACT } \\
U\end{array}$ & $\begin{array}{l}\text { c. THIS } \\
\text { PAGE } \\
\text { U }\end{array}$ & \\
\hline
\end{tabular}

18. NUMBER
OF
PAGES
23

10. SPONSORING/MONITORS
ACRONYM(S)
NASA; AIAA
11. SPONSORING/MONITORING
REPORT NUMBER
NASA/TM-2008-215303; AIAA-2008-
4579

4579 

